\title{
Oncogenic Signaling Is Dominant to Cell of Origin and Dictates Astrocytic or Oligodendroglial Tumor Development from Oligodendrocyte Precursor Cells
}

\author{
Nanna Lindberg, ${ }^{1,2,3}$ Yiwen Jiang, ${ }^{1 \star}$ Yuan Xie, ${ }^{1 *}$ Hamid Bolouri, ${ }^{3}$ Marianne Kastemar, ${ }^{1}$ Tommie Olofsson, ${ }^{4}$ \\ Eric C. Holland, ${ }^{2,3,5}$ and Lene Uhrbom ${ }^{1}$ \\ ${ }^{1}$ Department of Immunology, Genetics and Pathology, Science for Life Laboratory, Uppsala University, Rudbeck Laboratory, SE-75185 Uppsala, Sweden, \\ ${ }^{2}$ Department of Cancer Biology and Genetics, and The Brain Tumor Center, Memorial Sloan-Kettering Cancer Center, New York, New York 10065, ${ }^{3}$ Human \\ Biology Division and Solid Tumor Translational Research, Fred Hutchinson Cancer Research Center, Seattle, Washington 98109, ${ }^{4}$ The National Board of \\ Forensic Medicine, Department of Forensic Medicine, SE-75140 Uppsala, Sweden, and 5 Department of Neurosurgery and Alvord Brain Tumor Center, \\ University of Washington, Seattle, Washington 98195
}

Stem cells, believed to be the cellular origin of glioma, are able to generate gliomas, according to experimental studies. Here we investigated the potential and circumstances of more differentiated cells to generate glioma development. We and others have shown that oligodendrocyte precursor cells (OPCs) can also be the cell of origin for experimental oligodendroglial tumors. However, the question of whether OPCs have the capacity to initiate astrocytic gliomas remains unanswered. Astrocytic and oligodendroglial tumors represent the two most common groups of glioma and have been considered as distinct disease groups with putatively different origins. Here we show that mouse OPCs can give rise to both types of glioma given the right circumstances. We analyzed tumors induced by K-RAS and AKT and compared them to oligodendroglial platelet-derived growth factor B-induced tumors in $C t v-a$ mice with targeted deletions of $C d k n 2 a$ $\left(\mathrm{p} 16^{\text {Ink4a-I- }}, \mathrm{p} 19^{\mathrm{Arf}-1-}, \mathrm{Cdkn} 2 \mathrm{a}^{-1-}\right)$. Our results showed that glioma can originate from OPCs through overexpression of K-RAS and AKT when combined with $\mathrm{p} 19^{\mathrm{Arf}}$ loss, and these tumors displayed an astrocytic histology and high expression of astrocytic markers. We argue that OPCs have the potential to develop both astrocytic and oligodendroglial tumors given loss of $\mathrm{p} 19^{\text {Arf }}$, and that oncogenic signaling is dominant to cell of origin in determining glioma phenotype. Our mouse data are supported by the fact that human astrocytoma and oligodendroglioma display a high degree of overlap in global gene expression with no clear distinctions between the two diagnoses.

Key words: astrocytoma; cell of origin; glioma; low-grade glioma; oligodendroglioma; PDGF

\section{Introduction}

Glioma is a collective term for astrocytoma, oligodendroglioma, and ependymoma of malignancy grades I-IV. The majority of gliomas are astrocytic or oligodendroglial tumors of grades II-IV that primarily affect adults (Ostrom et al., 2013), and these two groups of diffuse glioma are considered as separate diagnoses

Received July 8, 2014; revised Sept. 12, 2014; accepted Sept. 18, 2014.

Author contributions: N.L. and L.U. designed research; N.L., Y.J., Y.X., H.B., and M.K. performed research; E.C.H. contributed unpublished reagents/analytic tools; N.L., Y.X., H.B., T.O., and L.U. analyzed data; N.L. and L.U. wrote the paper.

This work was supported by grants to L.U. from the Swedish Cancer Society, the Swedish Childhood Cancer Foundation, the Association for International Cancer Research, the Swedish Society of Medicine, and Ragnar Söderberg's Foundation; and to N.L. by the Wenner-Gren Foundation, the Sweden-America Foundation, and the Swedish Research Council.

${ }^{*} Y . J$. and Y.X. contributed equally to this work.

The authors declare no competing financial interests.

Correspondence should be addressed to either Lene Uhrbom at the above address, E-mail: lene.uhrbom@igp.uu.se; or Nanna Lindberg, Human Biology Program, Fred Hutchinson Cancer Research Center, 1100 Fairview Avenue N., P0 Box 19024, Seattle, WA 98109, E-mail: nlindber@fhcrc.org.

Present address of N. Lindberg and E.C. Holland: Human Biology Program, Fred Hutchinson Cancer Research Center, 1100 Fairview Avenue N., PO Box 19024, Seattle, WA 98109.

DOI:10.1523/JNEUROSCI.2977-14.2014

Copyright $\odot 2014$ the authors $\quad 0270-6474 / 14 / 3314644-08 \$ 15.00 / 0$ with different prognosis and biology (Louis et al., 2007). Mutations of IDH1/2 is the most common genetic aberration in both astrocytoma (grade II) and oligodendroglioma (grade II; Yan et al., 2009). Patients diagnosed with oligodendroglioma (grade II) have a better prognosis than patients with astrocytoma (grade II; Smith et al., 2008; Bauman et al., 2009). This is associated with the frequent loss of $1 \mathrm{p} / 19 \mathrm{q}$ in oligodendroglial tumors connected with better response to chemotherapy (Sanai et al., 2011). In astrocytoma, IDH1/2 mutations are instead commonly combined with TP53 mutations, which is a significant prognostic marker for shorter survival (Kim et al., 2010). However, glioma patients with IDH1/2 wild-type tumors of all types and grades have significantly shorter survival than those with IDH1/2 mutations (Nobusawa et al., 2009; Sanson et al., 2009).

The cell of origin for astroglial and oligodendroglial tumors are proposed to be different (Louis et al., 2007), but these assumptions are circumstantial and based on the morphological similarities of tumor cells to the corresponding normal cells. The cell of origin for these tumors have not been proven but the most common belief is that gliomas arise from a common stem cell origin. The current understanding that oligodendroglioma (grade II) and anaplastic oligodendroglioma (grade III) cannot 
progress into glioblastoma (grade IV) while astrocytoma (grade II) and anaplastic astrocytoma (grade III) are considered highly prone to progress into secondary glioblastoma (grade IV) argues for distinctly different biology of astrocytic and oligodendroglial tumors inferred by their assumed different origins. An alternative hypothesis is that these two histopathologically distinct types of glioma could be the result of different evolutionary paths that started in the same cell of origin.

Previously we showed that platelet-derived growth factor B (PDGF-B) could induce development of oligodendroglial tumors (grades II and III) from oligodendrocyte precursor cells (OPCs; Lindberg et al., 2009). Several subsequent reports have corroborated that glioma can arise from OPCs (Persson et al., 2010; Hambardzumyan et al., 2011; Liu et al., 2011), and tumors were described as showing typical oligodendroglial histology. Further, for two of the OPC-derived glioma models, global gene expression analysis showed an enrichment for OPC markers (Persson et al., 2010; Liu et al., 2011). In vitro, oligodendrocyte/ type-2 astrocyte progenitor cells (O-2A/OPC) progenitor cells and glial restricted precursor cells (GRPs) can be transformed using combinations of epidermal growth factor receptor variant III and dominant-negative p53. Transformed O-2A cells formed oligodendroglial tumors upon in vivo transplantation while GRPs formed astrocytomas (Wang et al., 2013). Here we show that OPCs can be a common origin for both astrocytic and oligodendroglial tumors given that the accurate oncogenic signaling is provided. This argues for the possibility that oligodendroglial versus astroglial fate is dependent on the oncogenic mutations used while the originating cell type seems to be important for the susceptibility of a particular oncogene to cause tumor development.

\section{Materials and Methods}

Animal experiments. Ctv- $a$ transgenic mice (Lindberg et al., 2009) were crossed with p16 ${ }^{\text {Ink4a }}$-deficient (Sharpless et al., 2001), p19 ${ }^{\text {Arf }}$-deficient (Kamijo et al., 1997), or p16 ${ }^{\text {Ink4a }} /$ p19 ${ }^{\text {Arf }}$-deficient (Serrano et al., 1996) mice. Tumors were induced in neonatal (postnatal day 1) mice of either sex by intracerebral injection of DF-1 chicken fibroblasts producing RCAS (replication-competent leukosis virus splice acceptor)-PDGF-B-ires-eGFP (Dai et al., 2001) or RCAS-AKT (Aoki et al., 1998) and RCAS-K-RAS (Holland et al., 2000). Mice were killed upon sign of illness or at 12 weeks of age and formalin-fixed paraffin-embedded (FFPE) processed.

In situ characterization of infected cells. Neonatal Ctv-a mice of either sex were injected intracerebrally using DF-1 cells expressing RCASEGFP, killed 5 or $7 \mathrm{~d}$ postinjection and brains FFPE processed for immunofluorescent stainings (mouse anti-GFAP, rabbit anti-OLIG2, and rabbit anti-NG2 from Millipore; mouse anti-nestin from BD Biosciences; rabbit anti-Musashil and chicken anti-GFP from Abcam; Alexa Fluor anti-chicken 488 and anti-rabbit or anti-mouse 555 from Invitrogen). Slides were mounted in ImmuMount (Shandon) containing DAPI and pictures were taken using a Leica DMI 400B microscope.

Immunohistochemical analysis of tumors. Following deparaffinization, antigen retrieval was done by pressure boiling in antigen unmasking solution, pH 4.0 (Vector Labs), pH 6.0 (DAKO), or 1 mM EDTA, pH 8.0, followed by immunohistochemical staining using Ultra Vision LP system (Lab Vision) or ABC Elite system and antibodies described previously (Lindberg et al., 2009). Slides were mounted in ImmuMount and pictures taken using a Leica bright-field microscope. CD44 (Abcam) and YKL40 (Bioss) stainings were done using an automated Ventana system. Images were taken using a Nikon E400 bright-field microscope.

Statistical analysis. Statistical analysis was done using GraphPad Software Prism 4.0. For group comparisons of incidence, Fisher's exact test was used. Log-rank test was used for survival curves and $\chi^{2}$ test was used for malignancy distribution.
The Cancer Genome Atlas low-grade glioma data analysis. We downloaded human glioma data from The Cancer Genome Atlas (TCGA) Data Portal [https://tcga-data.nci.nih.gov; number of samples: astrocytoma gliomas, 78; oligodendrogliomas, 100; oligoastrocytomas, 71; classical glioblastoma multiformes (GBMs), 148; mesenchymal GBMs, 155; proneural GBMs, 74; neural GBMs, 68; CpG island methylator phenotype GBMs, 21] and mapped common gene names between GBM and low-grade glioma samples. We then calculated the expression-level Pearson correlation for the common genes between all sample pairs and defined intersample distance as follows: 1 - correlation(sample1,sample2). The resulting distance matrix was passed to the $\mathrm{R}$ "cmdscale" (classical multidimensional scaling) function to generate a two-dimensional projection of expression similarity among the samples. Boxplots for individual gene expression levels were plotted using the R package "ggplot2" (http://ggplot2.org/).

\section{Results \\ Combined loss of Cdkn2a and oncogenic K-RAS+AKT enabled high-grade astrocytoma development from OPCs}

We have developed a mouse model, $C t v-a$, to study the role of OPCs in glioma development (Lindberg et al., 2009) and here we have used it further to investigate the biological consequences of an OPC origin for experimental glioma development. Previously we showed that PDGF-B could induce oligodendroglial tumors (grades II and III) from OPCs. Thus, it is evident that OPCs can be the origin of oligodendrogliallike tumors in mice. Could they also hold the potential of developing astrocytomas? Could their tumorigenic potential be triggered by loss of $C d k n 2 a$, which is one of the most commonly lost tumor suppressors and one of the earliest events in glioma (Ozawa et al., 2014)?

In the Ctv-a mouse 2', 3'-cyclic nucleotide 3'-phosphodiesterase (CNP)-expressing OPCs can be specifically infected by RCAS retroviruses to induce glioma development. To further define the target cell in $C t v$ - $a$ mice, neonatal mice were intracranially injected with RCAS-eGFP and infected cells detected and analyzed by immunohistochemistry for coexpression of GFP and neural/glial markers. RCAS-infected cells were found to be NG2 and OLIG2 positive (Fig. $1 A, B$ ) while negative for nestin, musashi1, SOX2, GFAP, and S100 $\beta$ (data not shown), establishing selective infection of OPCs.

To investigate whether OPCs could be susceptible to $\mathrm{K}-\mathrm{RAS}+\mathrm{AKT}$-induced gliomagenesis through loss of the $C d k n 2 a$ locus, we injected neonatal Ctv-a mice deficient for Ink $4 a$, Arf, or Ink4a-Arf and analyzed tumor incidence and malignancy grade after 12 weeks (Fig. $1 C, D$ ). Like $C t v$ - $a$ wild-type mice, $\operatorname{Ink} 4 a^{-/-}$mice were not susceptible to K-RAS+AKT-induced tumor development (Fig. 1C). Loss of Arf, however, allowed glioma development from OPCs and resulted in an incidence of 30 and 19\%, respectively, in $A r f^{-1-}$ and Ink4a-Arf ${ }^{-1-}$ mice (Fig. 1C). Tumor grade and histopathology were determined by a neuropathologist (T.O.) to be a World Health Organization grade III or IV malignancy (Fig. $1 D)$ and Arf-deficient mice suffered from significantly shorter survival compared with wild-type and $\operatorname{Ink} 4 a^{-/-}$mice (Fig. 1E). Loss of Arf was previously shown to allow tumor development from other differentiated GFAP-positive cells (Gtv-a mice) but was not required in less mature nestin-positive NSCs (Ntv-a mice; Uhrbom et al., 2002, 2005). Interestingly, and in accordance with previous K-RAS + AKT-induced gliomas from NSCs or astrocytic cells, all tumors displayed an astrocytoma-like histopathology (Fig. $1 F, G$ ) composed of a heterogenous mixture of glial and sarcomatous compartments resembling gliosarcomas (Fig. $1 F$ ). Many tumors also had ample areas of giant cells commonly found in giant cell glioblastoma (Fig. $1 G$ ). Studies in Ntv-a 

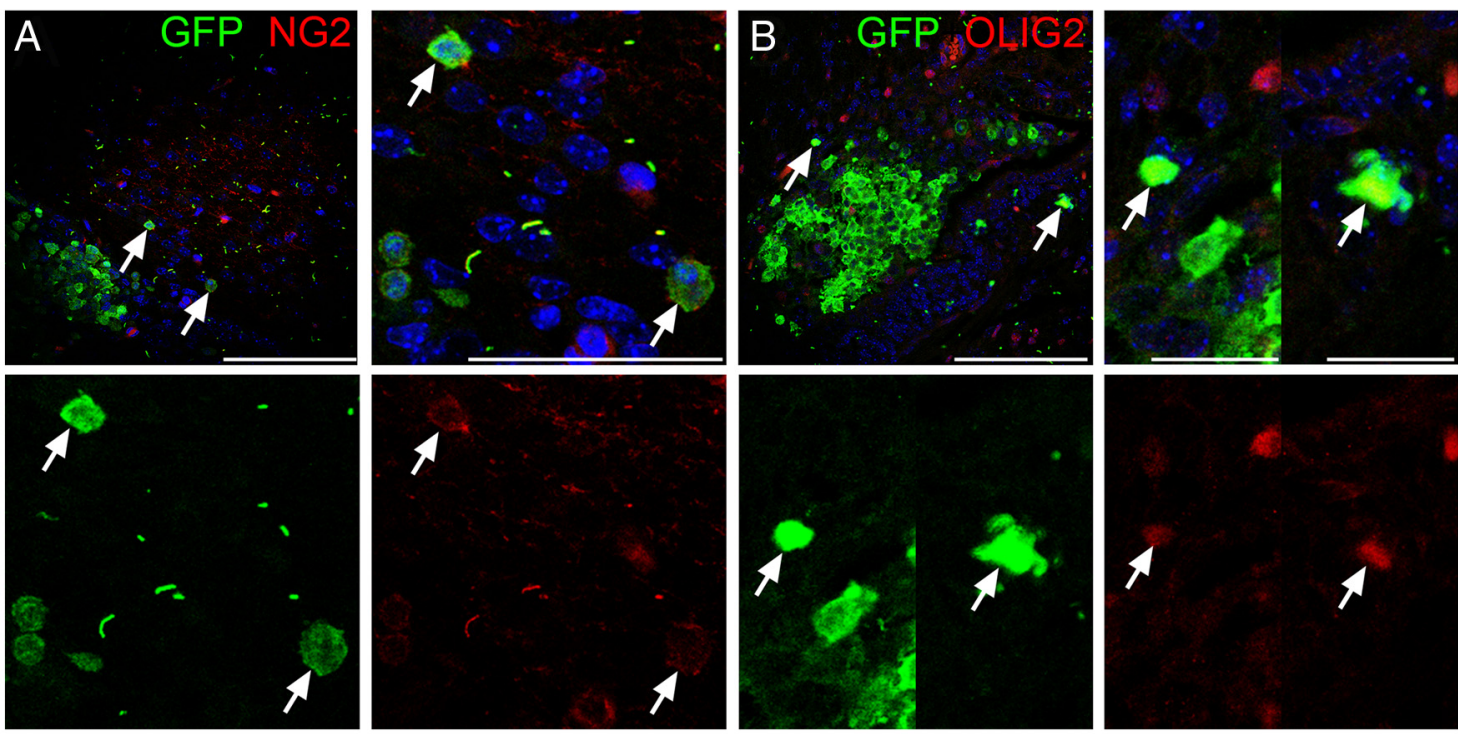

C
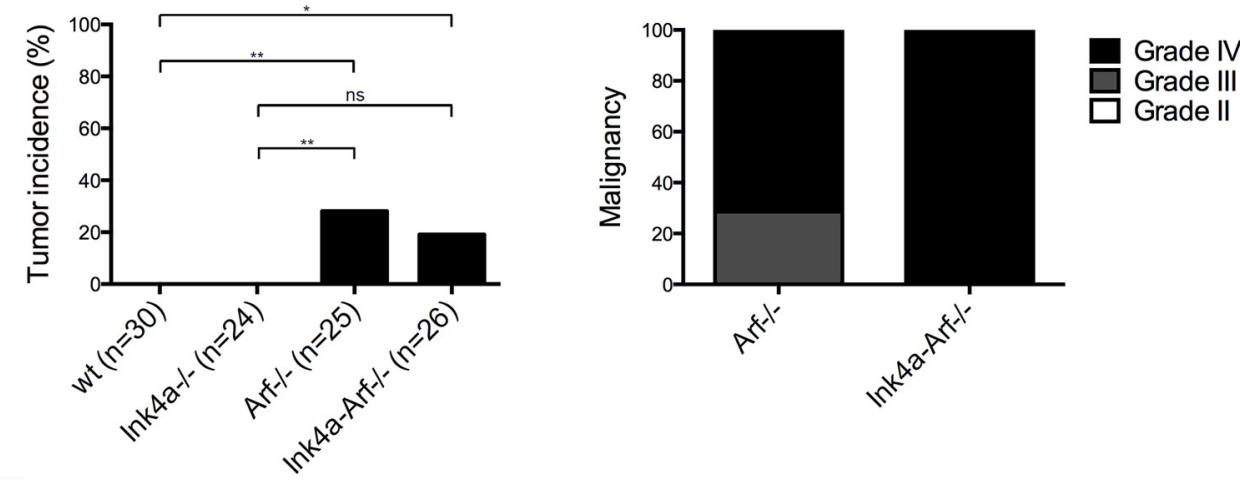

E
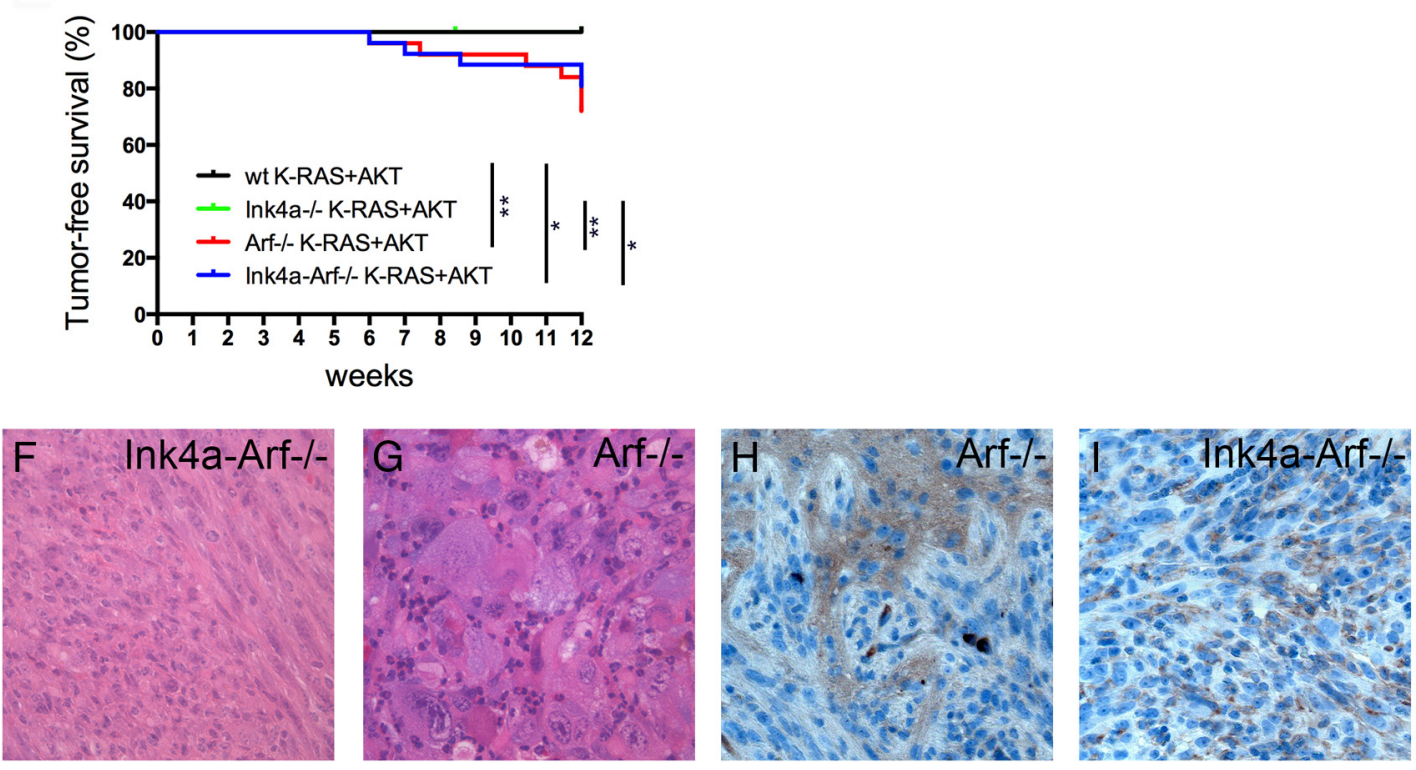

Figure 1. $\quad \boldsymbol{A}, \boldsymbol{B}$, Target cells of RCAS infection in (tv- $a$ mice. Arrows denote RCAS-EGFP-infected mouse cells (adjacent to injected RCAS-producing DF-1 cells) double-positive for GFP and ( $\boldsymbol{A}$ ) NG2 or ( $\boldsymbol{B})$ 0LIG2. Scale bars: $\boldsymbol{A}, \boldsymbol{B}$, top left, $100 \mu \mathrm{m} ; \boldsymbol{A}$, top right, $50 \mu \mathrm{m} ; \boldsymbol{B}$, top right, $25 \mu \mathrm{m}$. $\boldsymbol{C}-\mathbf{I}, \mathrm{K}$-RAS + AKT-induced astrocytic gliomas from OPCs. Loss of Arf or Ink4a-Arf resulted in $(\boldsymbol{C})$ increased

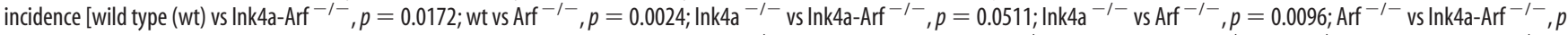
not significant], (D) high-grade tumors, and (E) decreased survival (Kaplan-Meier: wt vs Arf ${ }^{-1-}, p=0.002$; wt vs Ink4a-Arf ${ }^{-I-}, p=0.0124 ;$ Ink4a $^{-I-}$ vs Arf $^{-1-}, p=0.0064 ;$ Ink4a $^{-I-}$ vs $^{-}$ Ink4a-Arf $\left.{ }^{-I-}, p=0.0271\right) . F, G$, H\&E stained tumors. $\boldsymbol{H}, I$, Immunostainings for HA. 
A

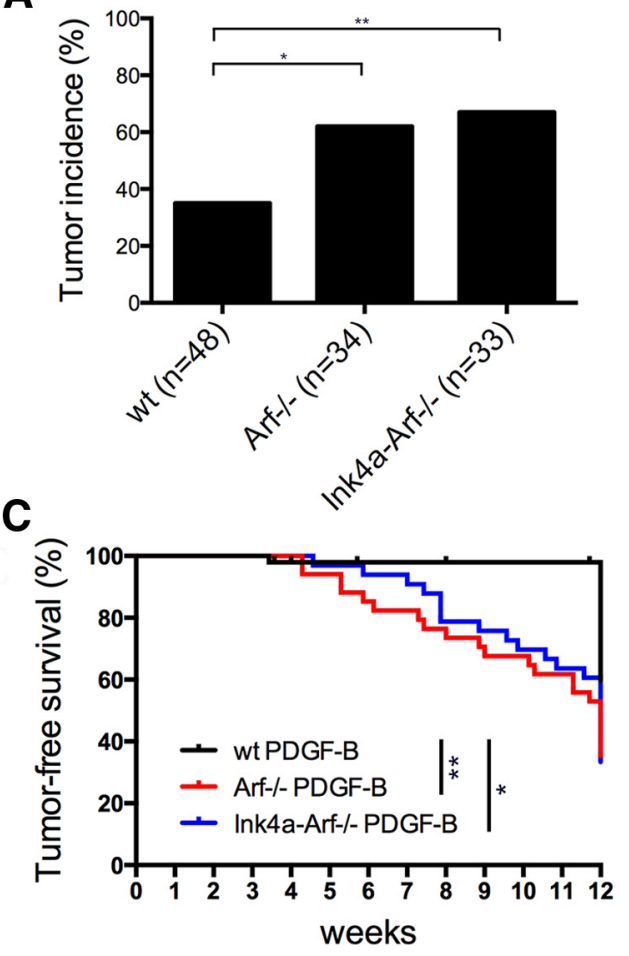

B
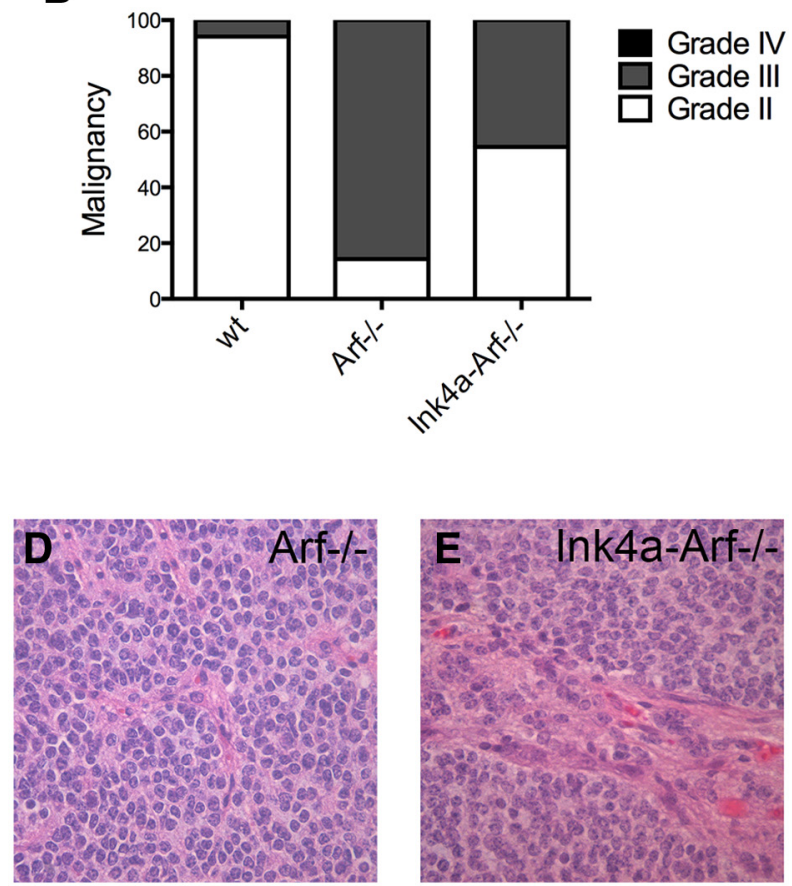

Figure 2. PDGF-B-induced gliomas in Ctv- $a$ mice. $\boldsymbol{A}-\boldsymbol{C}$, Loss of Arf or Ink4a-Arf caused $(\boldsymbol{A})$ increased tumor incidence [wild type (wt) vs Ink4a-Arf ${ }^{-/-}, p=0.0071 ;$ wt vs Arf ${ }^{-/-}, p=0.0249$ ],

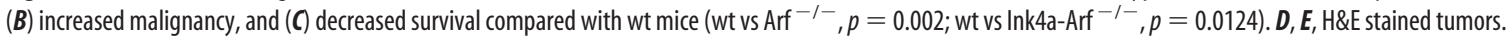

and Gtv- $a$ mice have shown that K-RAS alone can induce tumors (Uhrbom et al., 2005). We therefore analyzed the Ctv-al K-RAS + AKT tumors for expression of HA tagging the virally transduced AKT. All K-RAS + AKT tumors were positive for HA throughout the tumor tissue, strongly indicating that AKT was required to induce these tumors (Fig. $1 H, I$ ).

\section{Combined loss of Cdkn2a and overexpression of PDGF-B caused high-grade oligodendroglioma development}

Next we asked whether $C d k n 2 a$ loss was responsible for the astrocytic histopathology of the OPC-derived K-RAS + AKT tumors. To address this, Ctv-a wild-type, $A r f^{-/-}$, or Ink $4 a-$ $A r f^{-1-}$ mice were injected with RCAS-PDGF-B. Loss of Arf or Ink4a-Arf also accelerated PDGF-B tumor development, increased tumor incidence (Fig. 2A) and malignancy (Fig. 2B), and decreased survival (Fig. $2 C$ ). The histopathology of these tumors was, however, clearly different and in concordance with PDGF-B-induced tumors in Ctv- $a$ wild-type mice analogous to human oligodendroglioma of grades II and III (Fig. $2 D, E)$. Thus, OPCs could generate both astrocytic and oligodendroglial tumors, depending on the activated oncogenes and loss of tumor suppressor $C d k n 2 a$.

Astrocytic and oligodendroglial tumors displayed differential protein expression

To analyze whether the difference in histopathology of KRAS+AKT and PDGF-B tumors was reflected in the tumor phenotype, we compared expression of various glial proteins (Fig. 3). Nestin and GFAP showed homogenous expression in all K-RAS + AKT tumors while confined to vessels and, for GFAP also in reactive astrocytes, in PDGF-B tumors (Fig. $3 A, B$ ). K-RAS+AKT tumors were strongly positive for vimentin, indicating astrocytic differentiation, while PDGF-B tumors were completely nega- tive (Fig. 3C). The astrocyte precursor cell marker CD44 (Liu et al., 2004) was found throughout all tumors induced by K-RAS + AKT while restricted to perivascular areas of higher-grade PDGF-B tumors and absent in lower-grade PDGF-B tumors (Fig. 3D). K-RAS + AKT tumors also showed a higher expression of YKL40 (CHI3L1), a secreted glycoprotein that can differentiate between astrocytic and oligodendrocytic gliomas (Nutt et al., 2005; Fig. 3E).

Analysis of OPC markers showed that PDGFR $\alpha$ was expressed in all tumors (Fig. $3 F$ ), reflecting the inherent feature of the cell of origin (Barres et al., 1992). OLIG2, on the other hand, displayed an interesting difference (Fig. 3G). In K-RAS+AKT tumors, the overall expression of OLIG2 was highly variable. A subset of cells was clearly positive and many showed, in addition to a nuclear staining, a diffuse cytoplasmic staining. However, the majority of tumor cells were negative. In contrast, PDGF-B tumors had a high, homogenous, and defined nuclear OLIG2 expression in all tumor cells.

\section{Transcriptome analysis of human astrocytoma and} oligodendroglioma revealed indistinct molecular separation To investigate the relevance of our findings in human glioma, we used publicly available transcriptome data from low-grade astrocytoma (grade II) and oligodendroglioma (grade II) in the TCGA database. First we investigated the overall gene expression similarities and differences between the two groups in RNA sequencing data from 100 cases of oligodendroglioma (grade II) and 78 cases of astrocytoma (grade II). Multidimensional scaling analysis showed that oligodendrogliomas and astrocytomas were only partially separated and that there was a clear overlap between the groups (Fig. $4 A$ ). In contrast, all grade II tumors were well separated from the 466 cases of grade IV glioblastoma (Fig. 4B) 

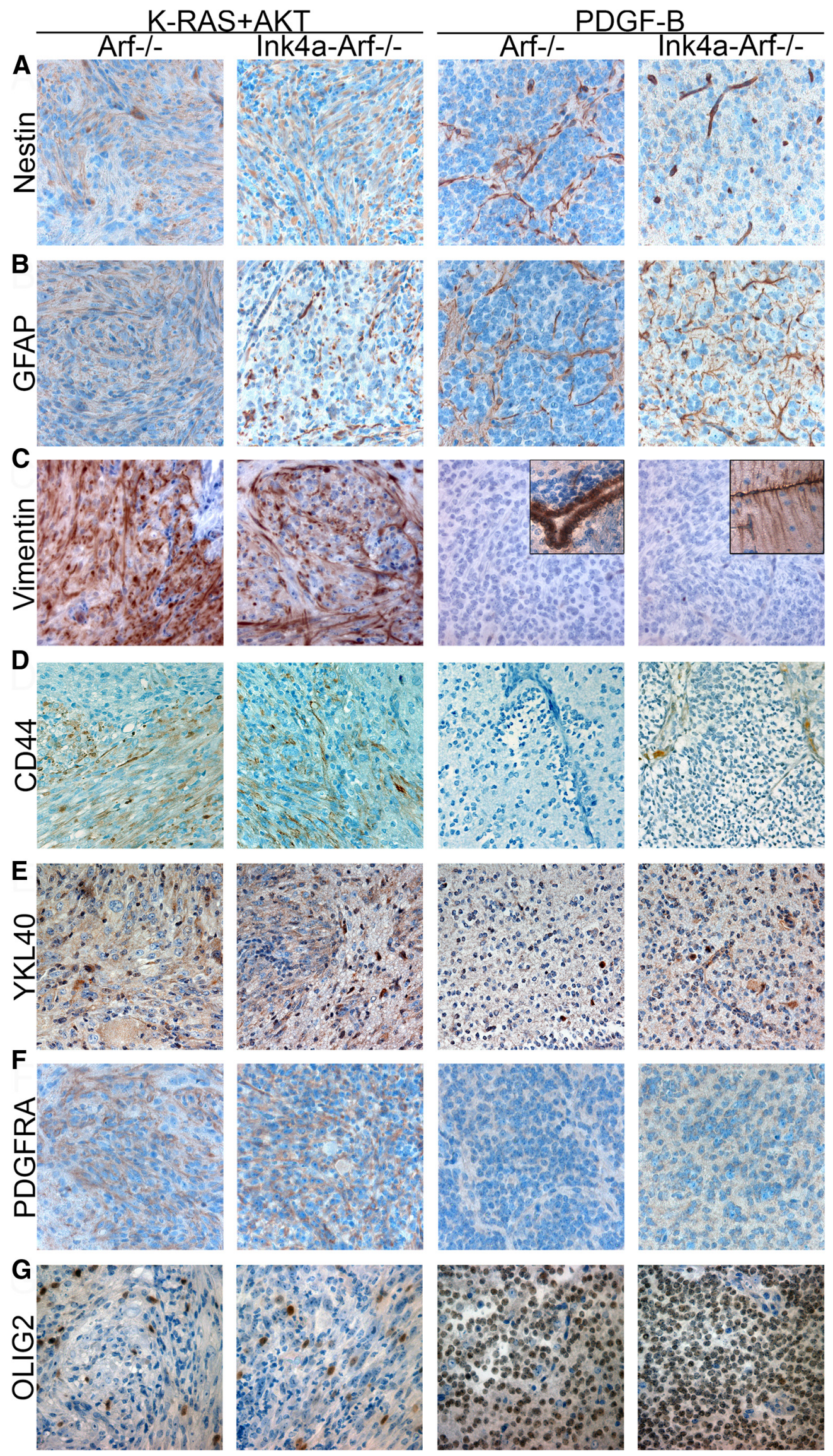

Figure 3. Glial marker expression in OPC-derived KRAS + AKT and PDGF-B tumors. $A-G$, Representative pictures of immunostainings for $(A)$ nestin, $(B)$ GFAP, $(C)$ vimentin (insets show expression in ependymal and Bergmann glial cells in the normal surrounding tissues, respectively), (D) CD44, (E) YKL40, (F) PDGFR $\alpha$, and (G) 0LIG2 in tumors from Ctv-a Arf ${ }^{-1-}$ and Ctv-a Ink4a-Arf ${ }^{-1-}$ mice induced by K-RAS + AKT or PDGF-B. 
A

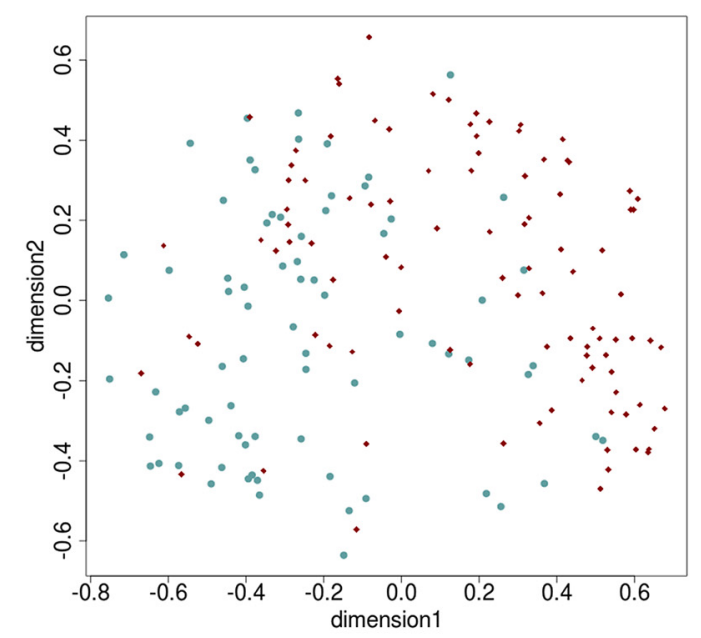

Astrocytoma

Oligodendroglioma
B

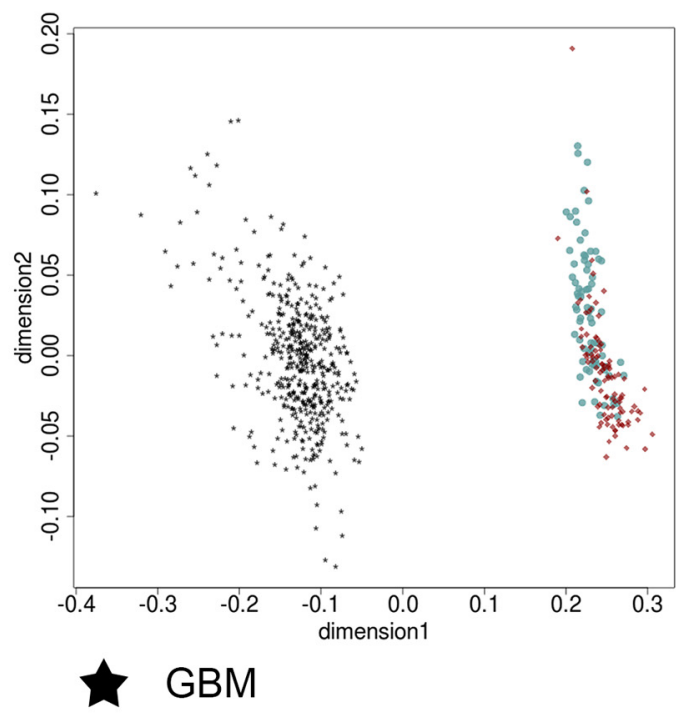

Astrocytoma

Oligodendroglioma

E
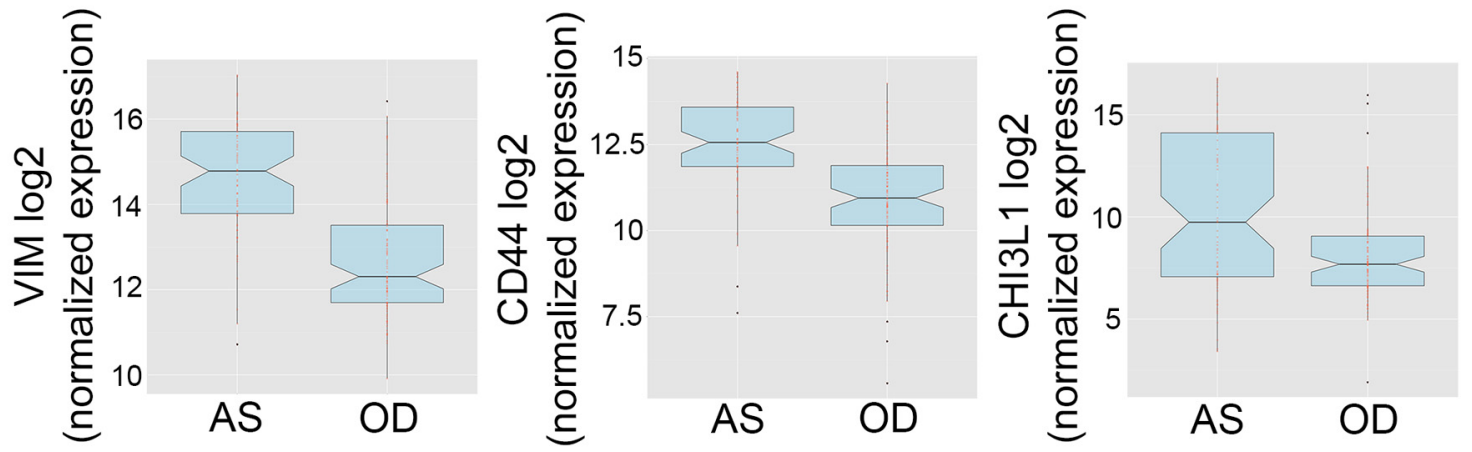

$\mathbf{F}$

G
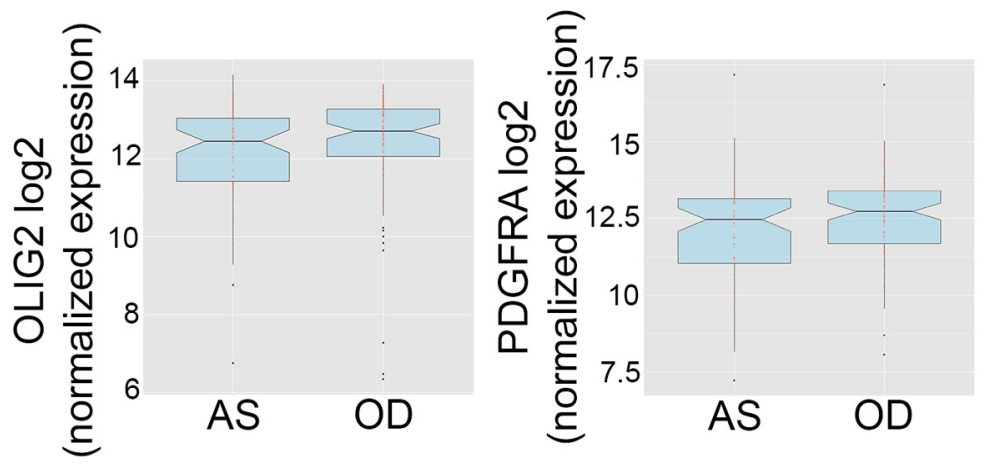

Figure 4. Comparative molecular analyses of human astrocytoma and oligodendroglioma from the TCGA database. $A, B, P C A$ analysis of global gene expression in human ( $A$ ) astrocytoma (grade II) and oligodendroglioma (grade II) and in (B) astrocytoma, oligodendroglioma, and glioblastoma (grade IV). C $-\mathbf{G}$, Gene expression in astrocytomas (AS) and oligodendrogliomas (OD) of (C) vimentin, (D) CD44, (E) CHI3L1, (F) 0LIG2, and (G) PDGFR $\alpha$.

The human dataset was analyzed for expression of genes that were differentially expressed on the protein level in the OPC-derived astrocytic and oligodendroglial mouse gliomas (Fig. 3). We found a significant difference in gene expression of vimentin, CD44, CHI3L1, and OLIG2 between human astrocytoma and oligodendroglioma (Fig. $4 C-F$ ) and, as for the mouse tumors, no difference in PDGFR $\alpha$ (Fig. 4G), supporting the relevance of the $C t v$ - $a$ mouse to model human glioma. 


\section{Discussion}

Astrocytoma and oligodendroglioma are by pathology considered as separate diagnoses with putatively different origins. Here we show that OPCs can be the origin of both astrocytic and oligodendrocytic gliomas and that these tumors mimic their human counterparts with regard to histology and phenotype. In support we also show that human astrocytoma and oligodendroglioma on the molecular level display a continuum with no clear separation, which argues for the possibility that some of these tumors could have a common origin. This is opposite to what has been found for human glioblastoma where tumors, inseparable by histology, can be divided into different molecular subtypes (Brennan et al., 2013).

The astrocytic and oligodendroglial mouse tumors could be distinguished by histopathology and differences in intratumoral distribution and expression of several proteins. In line with what has been found for human astrocytic tumors compared with human oligodendroglial tumors, the mouse astrocytic tumors displayed stronger tumor cell-bound GFAP expression (Mokhtari et al., 2005). In human glioma there is an inverse correlation between nuclear OLIG2 expression and expression of both nestin and GFAP (Kinjo et al., 2008), which agrees well with our findings. OLIG2 is a transcription factor important for maturation and differentiation of the oligodendrocyte lineage (Zhou et al., 2001), and is also expressed by SVZ type C progenitor cells that develop into oligodendrocytes and early OPCs (Menn et al., 2006). The higher OLIG2 expression in PDGF-B tumors could be due to a PDGF-induced expression of OLIG2 that has been shown to be dependent on Erk activation (Hu et al., 2008). On the contrary, AKT can induce nuclear export of OLIG2 in NSCs and has been shown to promote astrocytic differentiation (Setoguchi and Kondo, 2004).

The high and differential protein expression of vimentin, CD44, and YKL40 in K-RAS + AKT tumors further corroborated the astrocytic differentiation of these tumors. In the CNS, vimentin is mainly expressed in astrocyte precursor cells but also by some adult glial cell types, such as astrocytes and ependymal cells (Schnitzer et al., 1981). Moreover, in human oligoastrocytomas, expression of vimentin is coupled to the astroglial parts of the tumors (Louis et al., 2007). The mechanism by which vimentin is upregulated in KRAS+AKT gliomas remains to be investigated, but in sarcoma cells AKT has been shown to bind to and phosphorylate vimentin on Ser39, protecting it from caspase-induced proteolytic degradation (Zhu et al., 2011). In the KRAS+AKT gliomas, both vimentin and viral-transduced AKT was expressed in all parts of the tumors, which could indicate a similar mechanism.

In all, our data show that KRAS + AKT can induce high-grade astrocytic gliomas from late OPCs, while PDGF-B induces oligondendroglioma-like tumors from the same cell of origin. This implies that human astrocytic and oligodendroglial tumors also may have an OPC origin, and that the cell of origin is inferior to genetic aberrations in determining tumor histopathology. Cellular differentiation is a continuum rather than distinct stages separated by expression of specific proteins. Although all studies of CNPase expression in the CNS (Scherer et al., 1994; Yuan et al., 2002) thus far have shown CNPase to be expressed solely in late OPCs and oligodendrocytes, we cannot exclude the possibility that CNPase may also be expressed transiently or at low levels in other cell types. Nevertheless, the fact that one and the same cell of origin can give rise to different types of glioma offers one explanation as to why molecular separation of human astrocytoma and oligodendroglioma is imprecise. It also shows that on- cogenic mutations can produce expression of various neural/glial markers whose expression is uncoupled from that of the originating cell type. Recent large-scale analyses of human gliomas have revealed several different subtypes of tumors that differ in molecular profiles and response to treatment. Therefore, understanding the role of cellular origin for glioma biology in relation to their molecular subtypes is imperative to further increase the resolution of clinically relevant glioma subtypes and thus to better identify them.

\section{References}

Aoki M, Batista O, Bellacosa A, Tsichlis P, Vogt PK (1998) The akt kinase: molecular determinants of oncogenicity. Proc Natl Acad Sci U S A 95: 14950-14955. CrossRef Medline

Barres BA, Hart IK, Coles HS, Burne JF, Voyvodic JT, Richardson WD, Raff MC (1992) Cell death and control of cell survival in the oligodendrocyte lineage. Cell 70:31-46. CrossRef Medline

Bauman G, Fisher B, Watling C, Cairncross JG, Macdonald D (2009) Adult supratentorial low-grade glioma: long-term experience at a single institution. Int J Radiat Oncol Biol Phys 75:1401-1407. CrossRef Medline

Brennan CW, Verhaak RG, McKenna A, Campos B, Noushmehr H, Salama SR, Zheng S, Chakravarty D, Sanborn JZ, Berman SH, Beroukhim R, Bernard B, Wu CJ, Genovese G, Shmulevich I, Barnholtz-Sloan J, Zou L, Vegesna R, Shukla SA, Ciriello G, et al. (2013) The somatic genomic landscape of glioblastoma. Cell 155:462-477. CrossRef Medline

Dai C, Celestino JC, Okada Y, Louis DN, Fuller GN, Holland EC (2001) PDGF autocrine stimulation dedifferentiates cultured astrocytes and induces oligodendrogliomas and oligoastrocytomas from neural progenitors and astrocytes in vivo. Genes Dev 15:1913-1925. CrossRef Medline

Hambardzumyan D, Cheng YK, Haeno H, Holland EC, Michor F (2011) The probable cell of origin of NF1- and PDGF-driven glioblastomas. PLoS One 6:e24454. CrossRef Medline

Holland EC, Celestino J, Dai C, Schaefer L, Sawaya RE, Fuller GN (2000) Combined activation of Ras and Akt in neural progenitors induces glioblastoma formation in mice. Nat Genet 25:55-57. CrossRef Medline

Hu JG, Fu SL, Wang YX, Li Y, Jiang XY, Wang XF, Qiu MS, Lu PH, Xu XM (2008) Platelet-derived growth factor-AA mediates oligodendrocyte lineage differentiation through activation of extracellular signal-regulated kinase signaling pathway. Neuroscience 151:138-147. CrossRef Medline

Kamijo T, Zindy F, Roussel MF, Quelle DE, Downing JR, Ashmun RA, Grosveld G, Sherr CJ (1997) Tumor suppression at the mouse INK4a locus mediated by the alternative reading frame product p19ARF. Cell 91:649659. CrossRef Medline

Kim YH, Nobusawa S, Mittelbronn M, Paulus W, Brokinkel B, Keyvani K, Sure U, Wrede K, Nakazato Y, Tanaka Y, Vital A, Mariani L, Stawski R, Watanabe T, De Girolami U, Kleihues P, Ohgaki H (2010) Molecular classification of low-grade diffuse gliomas. Am J Pathol 177:2708-2714. CrossRef Medline

Kinjo S, Hirato J, Nakazato Y (2008) Low grade diffuse gliomas: shared cellular composition and morphometric differences. Neuropathology 28: 455-465. CrossRef Medline

Lindberg N, Kastemar M, Olofsson T, Smits A, Uhrbom L (2009) Oligodendrocyte progenitor cells can act as cell of origin for experimental glioma. Oncogene 28:2266-2275. CrossRef Medline

Liu C, Sage JC, Miller MR, Verhaak RG, Hippenmeyer S, Vogel H, Foreman O, Bronson RT, Nishiyama A, Luo L, Zong H (2011) Mosaic analysis with double markers reveals tumor cell of origin in glioma. Cell 146:209221. CrossRef Medline

Liu Y, Han SS, Wu Y, Tuohy TM, Xue H, Cai J, Back SA, Sherman LS, Fischer I, Rao MS (2004) CD44 expression identifies astrocyte-restricted precursor cells. Dev Biol 276:31-46. CrossRef Medline

Louis DN, Ohgaki H, Wiestler OD, Cavenee WK (2007) WHO classification of tumours of the central nervous system, fourth edition. Lyon, Franch: IARC.

Menn B, Garcia-Verdugo JM, Yaschine C, Gonzalez-Perez O, Rowitch D, Alvarez-Buylla A (2006) Origin of oligodendrocytes in the subventricular zone of the adult brain. J Neurosci 26:7907-7918. CrossRef Medline

Mokhtari K, Paris S, Aguirre-Cruz L, Privat N, Crinière E, Marie Y, Hauw JJ, Kujas M, Rowitch D, Hoang-Xuan K, Delattre JY, Sanson M (2005) Olig2 expression, GFAP, p53 and 1p loss analysis contribute to glioma 
subclassification. Neuropathol Appl Neurobiol 31:62-69. CrossRef Medline

Nobusawa S, Watanabe T, Kleihues P, Ohgaki H (2009) IDH1 mutations as molecular signature and predictive factor of secondary glioblastomas. Clin Cancer Res 15:6002-6007. CrossRef Medline

Nutt CL, Betensky RA, Brower MA, Batchelor TT, Louis DN, StemmerRachamimov AO (2005) YKL-40 is a differential diagnostic marker for histologic subtypes of high-grade gliomas. Clin Cancer Res 11:22582264. CrossRef Medline

Ostrom QT, Gittleman H, Farah P, Ondracek A, Chen Y, Wolinsky Y, Stroup NE, Kruchko C, Barnholtz-Sloan JS (2013) CBTRUS statistical report: primary brain and central nervous system tumors diagnosed in the United States in 2006-2010. Neuro Oncol 15 [suppl 2]:iil-56. CrossRef Medline

Ozawa T, Riester M, Cheng YK, Huse JT, Squatrito M, Helmy K, Charles N, Michor F, Holland EC (2014) Most human non-GCIMP glioblastoma subtypes evolve from a common proneural-like precursor glioma. Cancer Cell 26:288-300. CrossRef Medline

Persson AI, Petritsch C, Swartling FJ, Itsara M, Sim FJ, Auvergne R, Goldenberg DD, Vandenberg SR, Nguyen KN, Yakovenko S, Ayers-Ringler J, Nishiyama A, Stallcup WB, Berger MS, Bergers G, McKnight TR, Goldman SA, Weiss WA (2010) Non-stem cell origin for oligodendroglioma. Cancer Cell 18:669-682. CrossRef Medline

Sanai N, Chang S, Berger MS (2011) Low-grade gliomas in adults. J Neurosurg 115:948-965. CrossRef Medline

Sanson M, Marie Y, Paris S, Idbaih A, Laffaire J, Ducray F, El Hallani S, Boisselier B, Mokhtari K, Hoang-Xuan K, Delattre JY (2009) Isocitrate dehydrogenase 1 codon 132 mutation is an important prognostic biomarker in gliomas. J Clin Oncol 27:4150-4154. CrossRef Medline

Scherer SS, Braun PE, Grinspan J, Collarini E, Wang DY, Kamholz J (1994) Differential regulation of the $2^{\prime}, 3^{\prime}$-cyclic nucleotide $3^{\prime}$-phosphodiesterase gene during oligodendrocyte development. Neuron 12:1363-1375. CrossRef Medline

Schnitzer J, Franke WW, Schachner M (1981) Immunocytochemical demonstration of vimentin in astrocytes and ependymal cells of developing and adult mouse nervous system. J Cell Biol 90:435-447. CrossRef Medline

Serrano M, Lee H, Chin L, Cordon-Cardo C, Beach D, DePinho RA (1996) Role of the INK4a locus in tumor suppression and cell mortality. Cell 85:27-37. CrossRef Medline
Setoguchi T, Kondo T (2004) Nuclear export of OLIG2 in neural stem cells is essential for ciliary neurotrophic factor-induced astrocyte differentiation. J Cell Biol 166:963-968. CrossRef Medline

Sharpless NE, Bardeesy N, Lee KH, Carrasco D, Castrillon DH, Aguirre AJ, Wu EA, Horner JW, DePinho RA (2001) Loss of p16Ink4a with retention of p19Arf predisposes mice to tumorigenesis. Nature 413:86-91. CrossRef Medline

Smith JS, Chang EF, Lamborn KR, Chang SM, Prados MD, Cha S, Tihan T, Vandenberg S, McDermott MW, Berger MS (2008) Role of extent of resection in the long-term outcome of low-grade hemispheric gliomas. J Clin Oncol 26:1338-1345. CrossRef Medline

Uhrbom L, Dai C, Celestino JC, Rosenblum MK, Fuller GN, Holland EC (2002) Ink4a-Arf loss cooperates with KRas activation in astrocytes and neural progenitors to generate glioblastomas of various morphologies depending on activated Akt. Cancer Res 62:5551-5558. Medline

Uhrbom L, Kastemar M, Johansson FK, Westermark B, Holland EC (2005) Cell type-specific tumor suppression by Ink4a and Arf in Kras-induced mouse gliomagenesis. Cancer Res 65:2065-2069. CrossRef Medline

Wang J, Bushman J, Wang X, Mayer-Proschel M, Johnson M, Noble M (2013) Oligodendrocyte/type-2 astrocyte progenitor cells and glialrestricted precursor cells generate different tumor phenotypes in response to the identical oncogenes. J Neurosci 33:16805-16817. CrossRef Medline

Yan H, Parsons DW, Jin G, McLendon R, Rasheed BA, Yuan W, Kos I, Batinic-Haberle I, Jones S, Riggins GJ, Friedman H, Friedman A, Reardon D, Herndon J, Kinzler KW, Velculescu VE, Vogelstein B, Bigner DD (2009) IDH1 and IDH2 mutations in gliomas. N Engl J Med 360:765773. CrossRef Medline

Yuan X, Chittajallu R, Belachew S, Anderson S, McBain CJ, Gallo V (2002) Expression of the green fluorescent protein in the oligodendrocyte lineage: a transgenic mouse for developmental and physiological studies. J Neurosci Res 70:529-545. CrossRef Medline

Zhou Q, Choi G, Anderson DJ (2001) The bHLH transcription factor Olig2 promotes oligodendrocyte differentiation in collaboration with $\mathrm{Nkx2.2}$. Neuron 31:791-807. CrossRef Medline

Zhu QS, Rosenblatt K, Huang KL, Lahat G, Brobey R, Bolshakov S, Nguyen T, Ding Z, Belousov R, Bill K, Luo X, Lazar A, Dicker A, Mills GB, Hung MC, Lev D (2011) Vimentin is a novel AKT1 target mediating motility and invasion. Oncogene 30:457-470. CrossRef Medline 